\title{
Torres Vedras, um exemplo da organização e da estruturação do espaço urbano medieval português
}

\section{Carlos Guardado da Silva}

Doutor em História Medieval, Professor da Universidade de Lisboa, Faculdade de Letras, Centro de Estudos Clássicos. Lisboa [Lisboa] Portugal. <carlosguardado@campus.ul.pt>

\begin{abstract}
Resumo
Este é um estudo de caso desenvolvido em três momentos, de história urbana e de urbanismo medieval, aplicado à cidade de Torres Vedras, no qual o autor procurar identificar a sua matriz, assim como os principais elementos que condicionaram a organização e a estruturação do espaço urbano. Parte das origens do povoamento do sítio de Torres Vedras, independentemente da origem do nome, identifica a matriz romana na estruturação do espaço urbano, e termina com a organização do espaço da vila torriense no período medievo, sobretudo em torno dos principais edifícios do poder - a casa da Câmara ou o paço do Concelho, o paço régio, as quatro igrejas matrizes (Santa Maria, São Pedro, São Tiago e São Miguel), um convento, o castelo e a muralha com as suas portas - incluindo uma referência à judiaria. Neste estudo, de natureza empírica, o autor recorre, sobretudo, à pesquisa documental e à observação direta para analisar os dados recolhidos e interpretar a evolução urbana de Torres Vedras, para concluir, na senda de Isabel de Luna e Guilherme Cardoso, assim como de André Baptista, acerca da matriz urbana fundacional romana de Torres Vedras, condicionada, no período medievo, pela presença dos edifícios do poder que, a par das ruas, faziam a cidade, e contribuíam para definir a organização e a estruturação do espaço.
\end{abstract}

\section{Palavras-chave}

Torres Vedras (Portugal). História urbana. Urbanismo romano. Urbanismo medieval. Organização do espaço urbano medieval.

\section{Torres Vedras, an example of organization and structuration of the medieval portuguese urban space}

\begin{abstract}
This medieval urban planning and urban history case study on the city of Torres Vedras was developed over three moments in which the author seeks to identify its matrix, as well as the main elements that conditioned the organization and disposition of the urban area. Part of the origins of Torres Vedras's population, whatever the root for the name may be, identifies the roman matrix in the disposition of the urban area, and culminates in the organization of space during the medieval period, with a special focus on buildings that represented power - the city hall or the Council House, the royal palace, the four parish churches (Santa Maria, São Pedro, São Tiago and São Miguel), a monastery, the castle and the wall, encompassing its doors - including a reference to the Jewish quarter. In this empirical study, the author uses mainly documentary research and direct observation for the data analysis regarding the founding urban roman matrix of Torres Vedras, after which he concludes, in sync with Isabel de Luna, Guilherme Cardoso and André Baptista, about the founding urban roman matrix of Torres Vedras and its conditioning, in the medieval period, by the presence of buildings representing power that, paired with streets, would shape the city and contribute to define the organization and disposition of the urban area.
\end{abstract}

\section{Keywords}

Torres Vedras (Portugal). Urban history. Roman urban design. Medieval urban design. Medieval urban space organization. 


\section{Introdução}

A ocupação do sítio de Torres Vedras remonta pelo menos à I⿳a Idade do Ferro (Luna \& Cardoso, 2013, p. 462), tendo autores antigos procurado identificá-lo com Arandis, topónimo que a Geografia de Ptolomeu e o Itinerário de Antonino situam no Alentejo. Sítio para o qual, mais recentemente, Vasco Gil Mantas atribuiu a provável identificação com o Oppidum (praça fortificada) Chretina, que Ptolomeu localiza a cerca de $50 \mathrm{~km}$ a norte de Olisipo (Lisboa). Tratar-se-ia, neste caso, de uma aglomeração secundária que mereceu a atenção do geógrafo alexandrino talvez pela sua importância viária com a categoria de mansio (albergue), uma vez que se encontrava no limite de uma jornada.

Chretina é um nome de origem grega tardia, podendo estar relacionado com a palavra latina «creta», que significa argila, tão característica dos solos da região, com o sufixo [-ina] sugerindo uma formação a partir de um antropónimo, situação que ocorre duas vezes nos topónimos da Lusitânia transmitidos por Ptolomeu, de que são exemplo Chretina e Caecilia Metellina (Medellin).

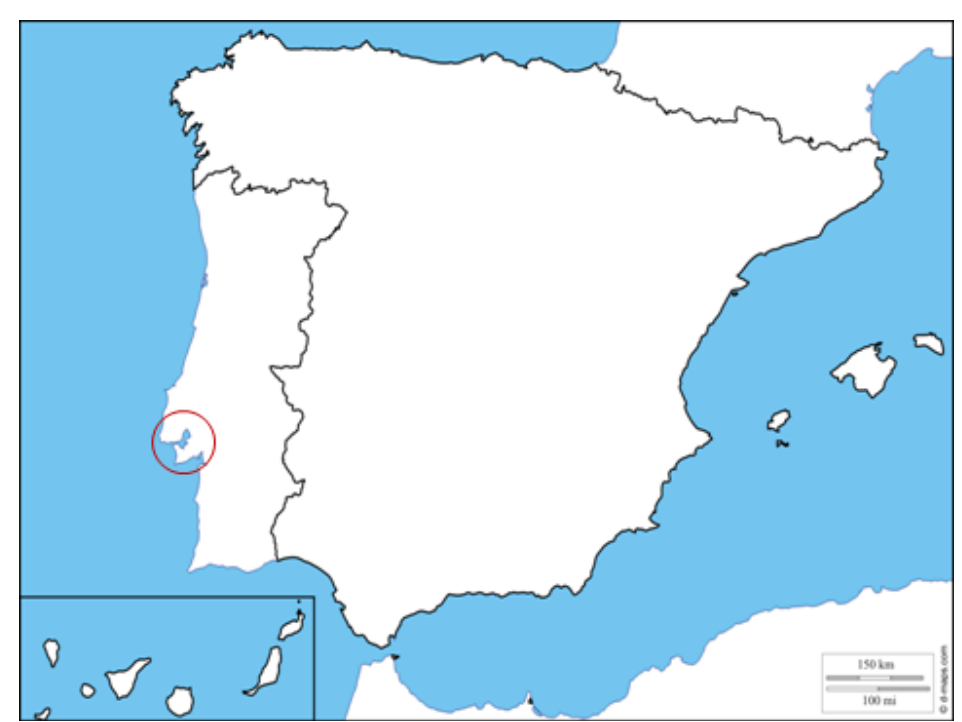

Figura 1. Península Ibérica.

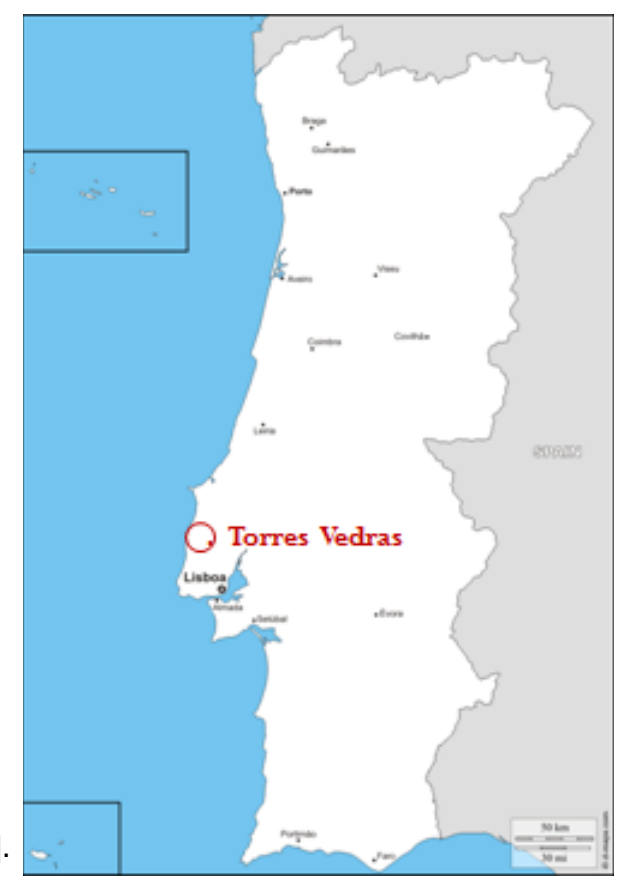

Figura 2. Localização de Torres Vedras [Portugal].

Deste então, o sítio - o topo do outeiro e a colina sul até à várzea - foi objeto de ocupação intensa e continuada, testemunhando-o a informação arqueológica relativa ao período romano, assim como à Idade Média. 0 próprio topónimo 'Torres Vedras', na sua forma medieval latinizada - Turres Veteras -, cuja data de fixação desconhecemos, remonta provavelmente à época clássica (ou à Alta Idade Média) aludindo a turris, fortificações locais arruinadas, torres velhas, porque antigas. Pois turris era um termo já usado no Império Romano, quer tivesse o significado de torre, como parece mais provável, quer fosse usado como equivalente de villa, não se atribuindo, neste caso, a uma povoação. Admitindo esta segunda hipótese, teríamos tido na sua origem uma villa romana que se distinguiria, de uma 'nova' ocupação, quer espacial quer cronologicamente, estendendo-se posteriormente ao sítio a designação de Turres Veteras ${ }^{1}$, aquando, muito provavelmente, de uma maior e mais intensa ocupação do espaço mais próximo da base da colina sul do sítio de Torres Vedras - elemento suficientemente identitário para se estender a todo o lugar e o território dele dependente, fixando o próprio topónimo, já de um vicus (lugar, aldeia).

\footnotetext{
${ }^{1}$ Tem-se tentado identificar a origem do topónimo Turres Veteras com os Túrdulos, mas nada o parece testemunhar.
} 


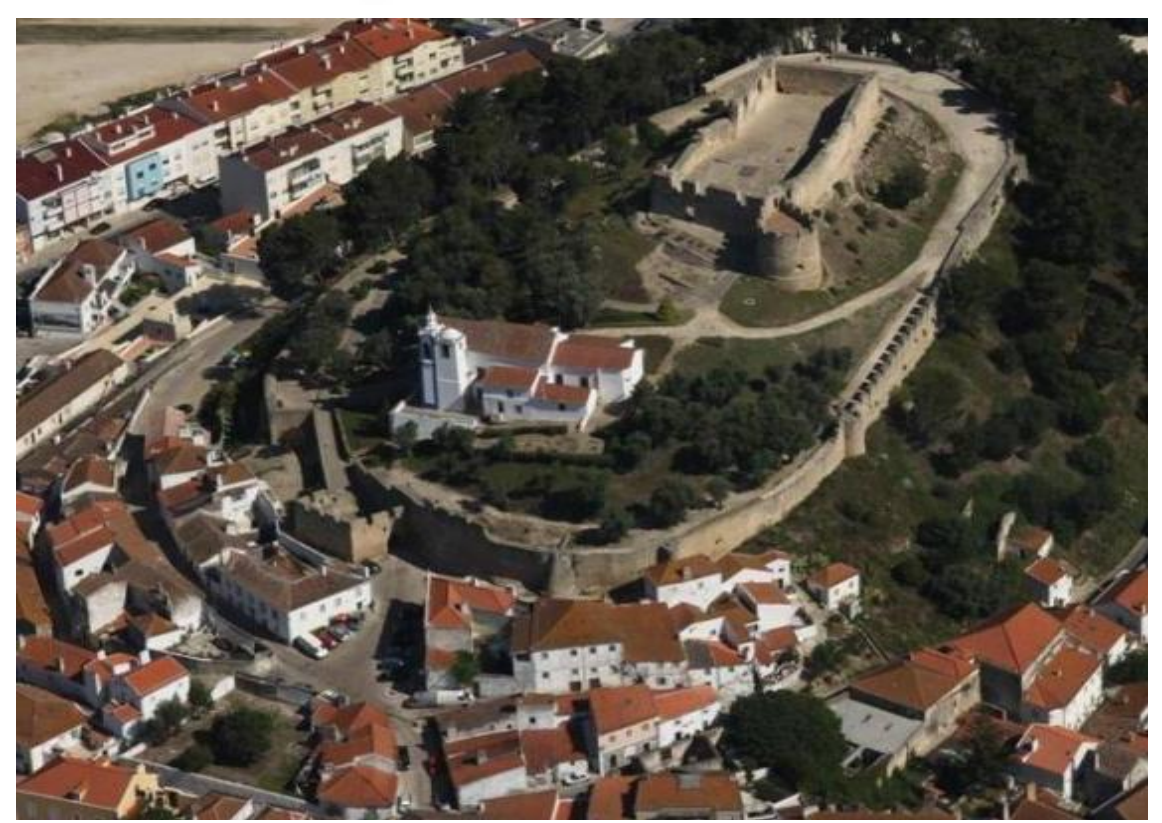

Figura 3. 0 sítio de Torres

Vedras. Fonte: Acervo do Autor.

\section{A Matriz romana: a estruturação do espaço}

Para além da informação arqueológica (incluindo a epigráfica e toponímica), a informação sobre Torres Vedras na Alta Idade Média é ainda escassa, encontrando-se ausente dos textos dos diversos autores árabes. Deste modo, também pouco sabemos acerca da estruturação do espaço urbano, que se teria reorganizado e consolidado com o domínio cristão de Torres Vedras, após a conquista da Linha do Tejo, em outubro de 1147. Isabel de Luna e Guilherme Cardoso, bem como André Baptista trouxeram-nos uma nova reinterpretação do espaço urbano de Torres Vedras, aqueles num estudo de síntese intitulado $A$ urbe de Torres Vedras e a sua cerca medieval (Luna e Cardoso, 2013, pp. 457-471) publicado já em 2015, este na sua dissertação de mestrado intitulada O lugar como simbiose: centro histórico de Torres Vedras (Baptista, 2013, p.58), leituras só possíveis quando elaboradas após décadas de investigação levada a cabo por aqueles sobre Torres Vedras, assim como na sequência de diversos outros estudos, publicados sobretudo nos últimos vinte anos.

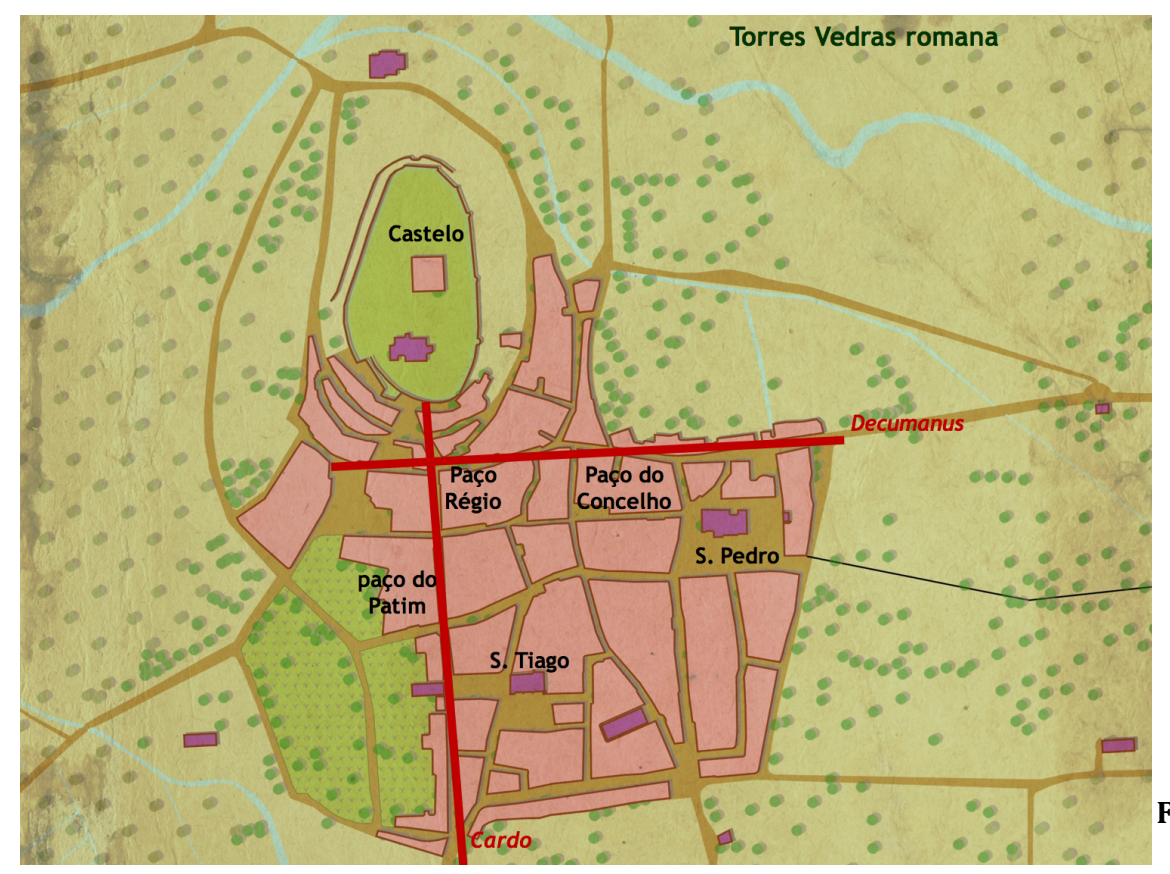

Figura 4. Torres Vedras romana²

2 Os mapas apresentados tiveram o apoio de Nuno Patrício, a quem agradecemos. 
Nestes estudos, é sublinhada uma matriz romana estruturante no desenvolvimento urbano da vila na Idade Média: o Cardo urbano, que corresponderia ao traçado da rua medieval dos Mercadores (rua dos Cavaleiros da Espora Dourada desde, pelo menos, 1776), e o eixo Decumanus (do oriente para ocidente), que corresponderia à rua do Paço, prolongando-se pelas ruas dos Canos e Corredoura (atual rua Cândido dos Reis). Na interseção dos eixos Cardo e Decumanus, teríamos uma praça, que o urbanismo medieval e moderno conservaram, junto do sítio onde se "ergueria", em finais do século XIII, o paço régio, por iniciativa de D. Beatriz.

Apesar da evolução urbana que a vila de Torres Vedras sofreu, até à atualidade, estes dois eixos afirmar-se-iam como estruturantes no desenvolvimento da urbe torriense, vincando a ideia de que o hisn islâmico, assim como o castelo cristão teriam sido usados apenas em caso de necessidade de defesa, acolhendo uma pequena guarnição militar, sendo o lugar habitado, sobretudo, fora das muralhas do castelo, na colina até à várzea. Esta interpretação infirma igualmente a hipótese de um povoamento que avançou, cronologicamente, de norte para sul, descendo paulatinamente a colina até ao seu sopé, quando temos vestígios de ocupação romana em diversos locais da vila baixa, desde o período da Republica. Para o mesmo espaço, a arqueologia permite documentar a continuidade do povoamento, de que são exemplo as escavações nos locais atualmente designados por Largo de Santo António, Rua dos Cavaleiros da Esporada Dourada (antigo paço do Patim), junto à igreja de São Tiago (2. ${ }^{\text {a }}$ Idade do Ferro e Romano) e no edifício Paços do Concelho (2. Idade do Ferro e Romano do período da Republica)(Baptista, 2013, p.61).

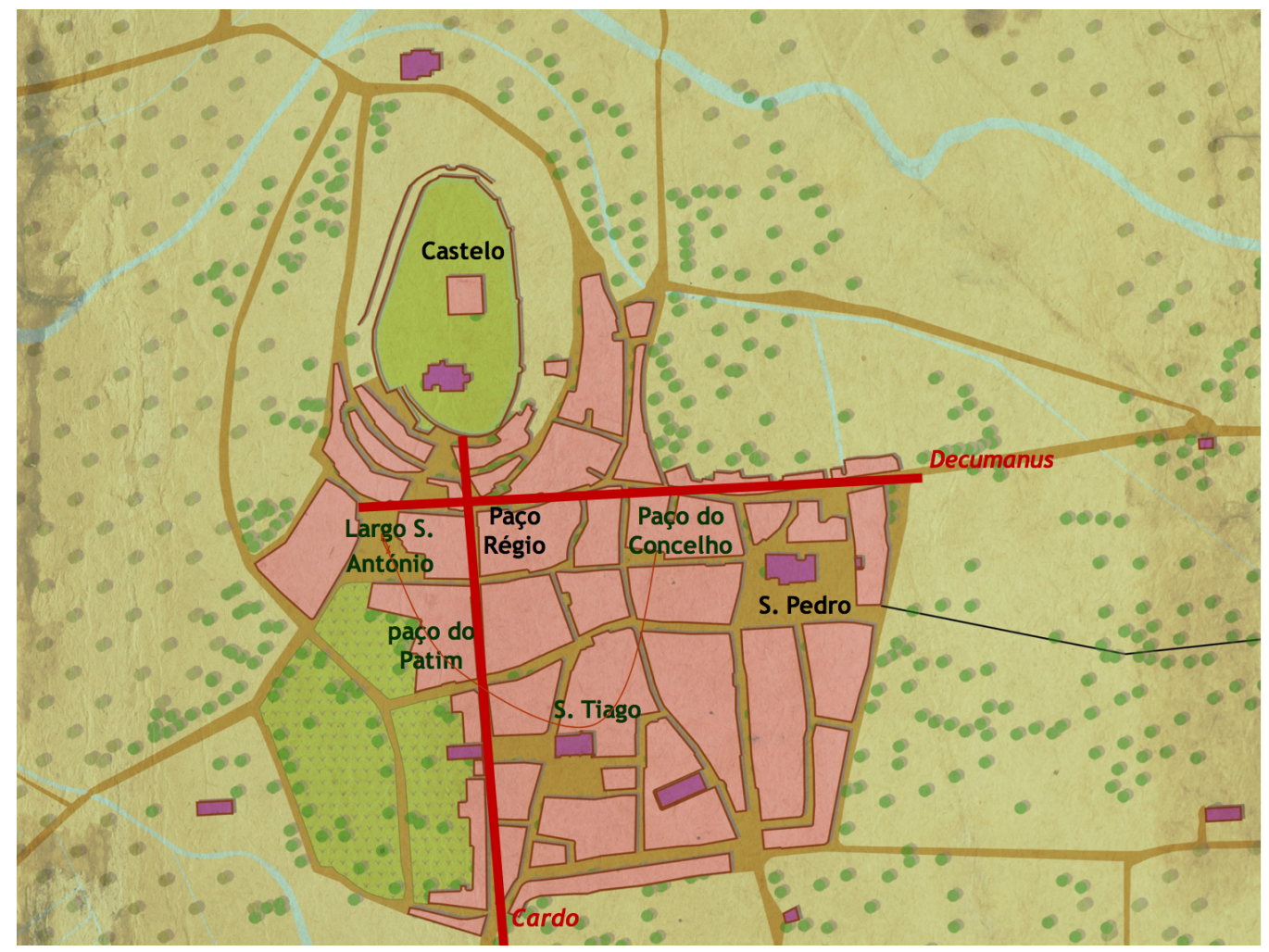

Figura 5. Torres Vedras romana.

Deste modo, estaríamos, em Torres Vedras, no período romano, na presença de um vicus, qualquer que fosse o seu nome, povoado que se desenvolveria a sul do oppidum, com vestígios de ocupação dos primeiros séculos da Era Cristã, referindo-se ou não as turres veteras à fortificação no cimo do monte. Tendo por base a informação arqueológica, o vicus ocuparia um espaço de dimensão considerável, toda a extensão do decumanus, espaço que viria a integrar o eventual traçado da muralha quatrocentista. No sentido norte-sul, compreenderia o espaço entre o castelo e, pelo menos, o já referido sítio onde se ergueria, no século XIII, a igreja matriz de São Tiago. Vicus (qarya em árabe), que se manteria até ao século XIII, estruturalmente marcado pelos dois eixos viários - Cardo e Decumanus -, bem como pelo oppidum/hisn, até à vila se colocar sob domínio cristão e, paulatinamente, se instituir o concelho, de iure, assim como as quatro paróquias medievais torrienses, determinantes na organização do espaço urbano. 


\section{A organização do espaço medieval}

A primeira referência a uma organização municipal, na vila de Torres Vedras, data do reinado de D. Sancho I (1185-1211), ainda que incipiente, testemunhando-o uma carta de doação régia, sem data, dirigida aos alcaides, juízes e concelhos das vilas situadas em torno do couto de Alcobaça, proibindo-os de praticar quaisquer exações contra os moradores do referido couto. A doação era feita pelo "foro da cidade de Lisboa, por dez mil libras de moeda portuguesa», em dinheiro contado, recebidas dos homens do Rei e vassalos de Torres Vedras, pela herdade que se chama Coutada. Torres Vedras possuía, desde então, uma organização municipal dotada com os respetivos magistrados, como defenderam Pedro Gomes Barbosa e Ana Maria Rodrigues, e cuja presença a documentação medieval atesta até á instituição do concelho de iure: os alcaides Monio Peres (1226), Garcia Fernandes (1228-1230), Pedro Anes (1232) e D. Afonso Martins (1249-1250), bem como os juízes Martim Borda (1230-1234) e Fernando Rodrigues (1246-1250).

A 15 de Agosto de 1250, encontrando-se em Évora, D. Afonso III doou carta de foral à vila de Torres Vedras. A constituição de autonomia exigia uma estrutura política e administrativa encarregue do governo dos destinos do concelho, assim como um edifício - casa da Câmara ou o paço do Concelho - que constituiria uma centralidade na vila medieval. Era o centro político e administrativo e, de certo modo, da justiça da urbe torriense, constituindo-se desde cedo também como centro económico, para onde concorriam os habitantes da vila e termo para a compra e venda de produtos no mercado que aí se fazia diariamente.

Defronte do Paço do Concelho, na Baixa Idade Média, situava-se uma grande «Praça», posteriormente registada como «Praça dos Víveres» ou «Praça do Município». A Praça, que se constituíra do alargamento da rua de S. Pedro, acolhia o Paço do Concelho, referido pela primeira vez em 1337, apesar do edifício, que aqui se encontra hoje, ser de feição moderna. No centro da Praça, localizava-se o pelourinho, cuja primeira referência data de 1430, tendo sido demolido em 1852, uma vez que estorvava a passagem do coche da rainha numa das suas visitas à vila. Da Praça, partiam as ruas da Praça, para norte, e da Ferraria, prolongando-se pela do Açougue [dos Clérigos], em frente - onde vários artesãos e comerciantes exerciam o seu mester e vendiam os seus produtos, fazendo desta a zona mais animada e concorrida da vila.

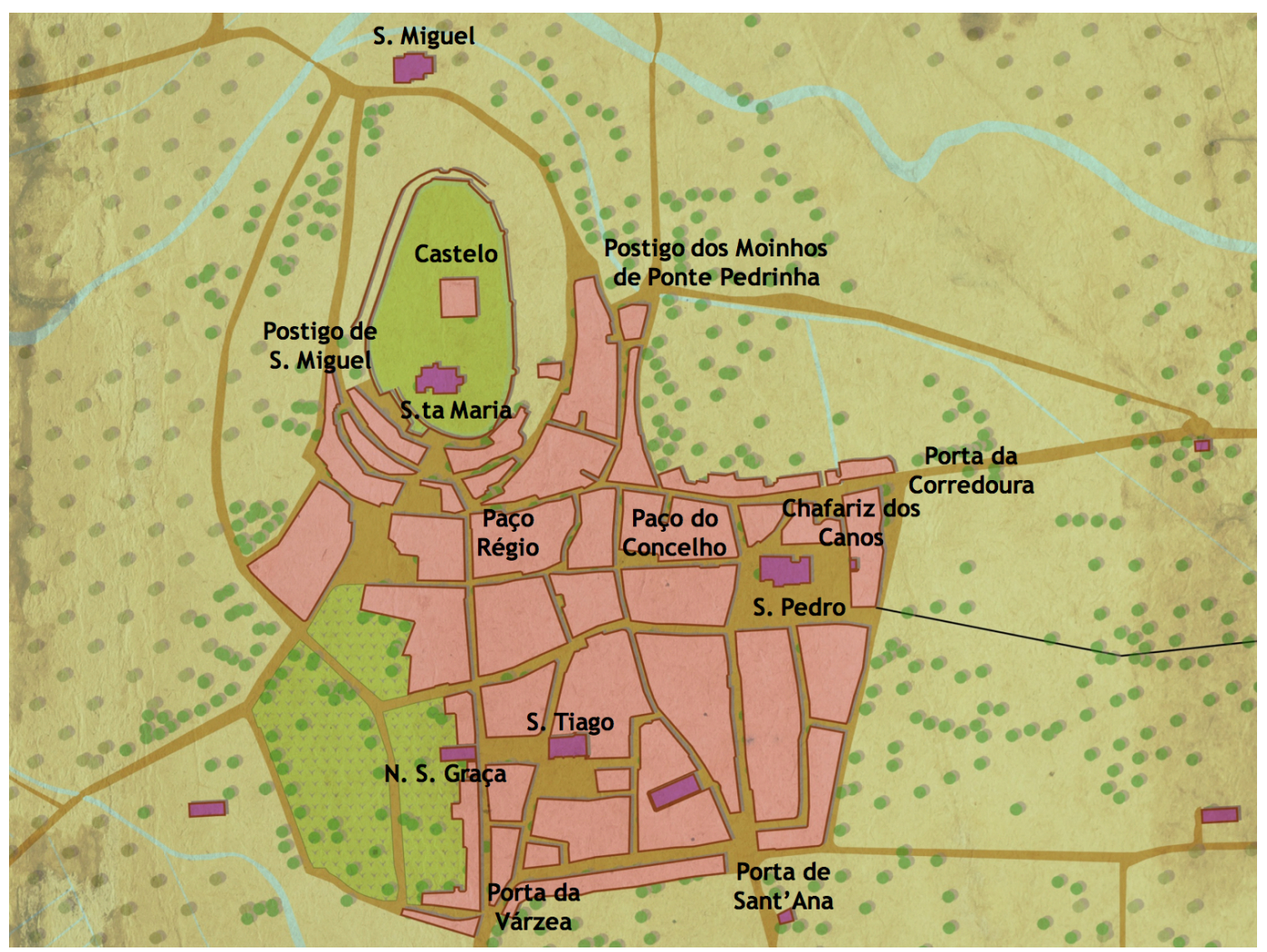

Figura 6. Torres Vedras medieval. 


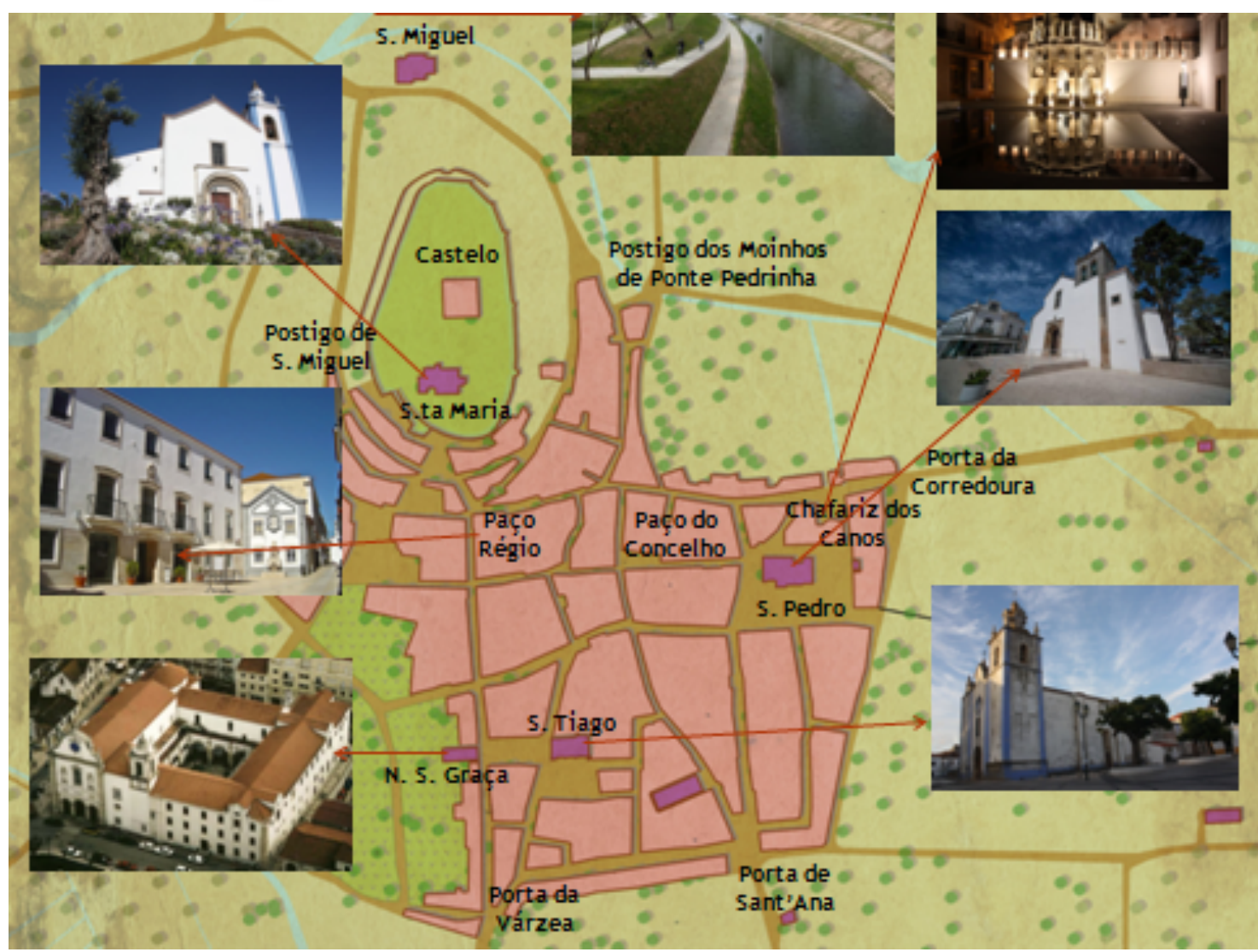

Figura 7. Torres Vedras medieval.

$\mathrm{Na}$ esquina entre a rua dos mercadores e a rua que descia a colina correndo para os Canos, D. Beatriz edificou, em finais do século XIII, um Paço, referência suficientemente importante para se fixar a designação de rua do Paço. Desde então, o Paço no castelo, residência eventual dos nossos primeiros reis nas suas curtas estadias na vila, foi abandonado ao alcaide e à guarnição.

0 paço não teria sido construído de raiz, tendo resultado da reunião de distintas parcelas e casas, adquiridas ou edificadas em diferentes momentos, à medida das necessidades e, sobretudo, das oportunidades de compra, como atesta uma aquisição feita por D. Beatriz, em 1293, de uma casa na freguesia de Santa Maria, que confrontava de três lados com propriedades suas e do quarto com a rua pública. Confrontações que denunciam uma intenção anterior de reunião de bens no mesmo local. Seis anos mais tarde, juntou-lhe outra casa quase nas mesmas condições, confrontando de duas partes com a soberana, da terceira com uma casa de mercê, e da quarta com a rua e metade de um campo (Figaniere, 1859, pp. 252-255).

No início de Trezentos, D. Dinis continuou o processo iniciado por sua mãe, comprando uma casa ante os paaços del Rey, e instalando uma capela privativa num edifício contíguo, pertencente à igreja de São Miguel. Ao emprazar, em 1318, todas as casas que a colegiada tinha junto do Açougue, o procurador do prior não se esqueceu de sublinhar saluo o sobrado hu El Rej faz ssa Capella e o sótão da dicta capella ficar com nas dictas casas. Estas confrontavam com casas del Rey e não com o Paço que, em anos posteriores, as escrituras sempre registaram. Talvez a ideia de que o palácio real pertencia à rainha e não ao rei o justifique, tendo sido as casas adquiridas pelo monarca.

A partir de D. Dinis, não terão existido quaisquer aquisições de bens pelos monarcas sucessores, visando ampliar e melhorar as suas instalações em Torres Vedras, testemunho de que o paço do rei ou da rainha - assim chamado, consoante era um ou outro que detinha o senhorio da vila, tinha atingido a sua extensão definitiva mantida até à sua substituição pelo paço novo da vila, mandado erigir, no século XVI, pela infante D. Maria, filha de D. Manuel. 
A presença do Paço Régio contribuiu decerto para a obrigatoriedade do calcetamento da rua onde se encontrava, embelezando e enobrecendo uma das principais vias da vila medieval. Aspetos urbanísticos considerados pela toponímia e que os documentos medievais registaram, pelo menos desde 1335. Testemunham-no as referências à Calçada a par dos paços d'El Rej ou à Calçada que uay pera Santa Maria do Castelo, designações distintas explicadas pelos diferentes posicionamentos do caminhante. A sua localização também o exigia, uma vez que a rua unia importantes centros de poder da vila - o castelo, o paço do concelho e as igrejas matrizes -, tornando-a um dos itinerários mais solenes da urbe, que necessitava, também por essa razão, de um acesso fácil e digno.

No paço teve lugar, nas vésperas de São Tiago de 1414, a reunião do Conselho Régio, presidida por D. João I, decisiva na preparação da armada com destino à conquista de Ceuta (de que se comemorou em 2015 o 6. centenário). 0 mesmo edifício que, cerca de duas décadas depois, viu nascer, em 1434, a infante D. Leonor, filha de D. Duarte, que viria a ser imperatriz da Germânia, por casamento com Frederico III.

Próximo do Paço do Concelho, localizava-se a Judiaria, cuja existência em Torres Vedras remonta pelo menos ao reinado de D. Afonso III (1248-1279), já com a presença de um "capelão" dos judeus, atestando indiretamente, a existência de sinagoga e, consequentemente, a presença na vila de uma comunidade judaica considerável. A constituição da judiaria, de iure, teria lugar com D. Afonso IV (1325-1357), dotando-a então de foros e privilégios que, na sequência de seu pai, obrigara os judeus a morarem em bairro próprio. Todavia, já em 1299 a família judaica Guedelha morava em casas contíguas, nomeadamente Isaac Guedelha e D. Judas Guedelha, rabi-mor de D. Dinis e provável irmão de Salomão Guedelha, o rabi dos judeus em Torres Vedras em 1318. Todavia, a documentação apenas se refere à Judiaria no final do reinado do rei poeta, sendo citado um filho de João Pais «da Judaria», em 1322. Deste modo, a Judiaria já marcaria a vila medieval em finais do século XIII, ainda que só se tenha constituído formalmente no reinado de D. Afonso IV.

A Judiaria torriense ocupava uma só rua (no sítio da atual rua dos Celeiros de Santa Maria), onde, no início, conviviam homens das duas religiões. Mas a influência dos judeus de Torres Vedras, nomeadamente os rabi-mores de D. Dinis, D. Judas Guedelha e seu filho D. Guedelha, que lhe sucedeu no cargo em 1316, parecem ter contribuído para a sua remota existência, assim como para o recrudescimento da importância da sua comunidade, a que não seria alheia a participação da família Guedelha no arrabiado régio. Pois Em 1381, já vinte e cinco famílias judaicas (cerca de $10 \%$ da população) habitavam a vila de Torres Vedras, multiplicando-se o seu número a partir do século XV, tornando-se necessário o alargamento da Judiaria, em 1469.

Mas a religião oficial impunha-se, marcando igualmente a paisagem urbana, nomeadamente através das quatro igrejas matrizes, importantes centros organizadores e estruturadores do espaço urbano, congregando para si a freguesia - no sentido mais literal do termo ${ }^{3}$, sobre os quais exerciam a sua jurisdição: Santa Maria, São Pedro, São Tiago e São Miguel, esta erguida a norte do morro do castelo, na margem esquerda do rio Sisandro. Entre si traçavam-se, para além das delimitações visíveis, as fronteiras invisíveis, que estremavam os espaços de cada paróquia, definindo a quem os fregueses deveriam as suas obrigações. E entre os fregueses de cada igreja, estabeleciam-se laços de solidariedade, conferindo a cada homem um sentimento de pertença.

A freguesia de Santa Maria foi instituída logo após a ocupação cristã da Estremadura, em data posterior à conquista cristã da linha do Tejo, em finais de outubro de 1147, sendo a igreja paroquial de fundação mais antiga em território torriense ${ }^{4}$. A primeira referência à igreja data de 1220, existindo, enquanto sede de freguesia autónoma, até 4 de Novembro de 1859, data em que lhe foi anexada a paróquia de São Miguel por decreto patriarcal. A freguesia de São Pedro foi

\footnotetext{
3 Do latim filli ecclesiae, significando nas suas origens, literalmente, aqueles que são filhos de uma igreja, termo religioso que, curiosamente, daria origem a uma palavra civil - freguesia, ao invés do termo 'paróquia', palavra não religiosa de origem grega, de PARA —, que significa "ao lado, perto de", e OIKOS, que significa 'casa', pretendendo designar aqueles que moravam próximo de uma igreja, os vizinhos, que deu origem a uma palavra religiosa.
}

${ }^{4}$ Do edifício medieval, restam os vestígios de dois pórticos românicos. 
instituída após o domínio cristão da Estremadura, em 1225, data em que conhecemos a primeira referência à mesma, ou um pouco antes. A mais antiga menção à igreja de São Tiago data de 1225 (Silva, 2012, p. 126), tendo a paróquia sido instituída, neste ano ou no seguinte, na mesma altura em que se instituíra a igreja matriz de São Miguel, em 1226, se não antes.

A partir de uma carta de D. Afonso III é possível conhecermos a divisão primitiva do território das paróquias torrienses, talvez no primeiro quartel do século XIII, nomeadamente entre as matrizes de São Pedro, São Miguel e São Tiago. A partilha primitiva, entre estas, teria sido anterior a 1225, uma vez que nesse ano Martim Hoveques já se referia, ainda que indiretamente, à igreja de São Tiago, da qual seria muito provavelmente freguês. No século seguinte, resultado de um crescimento demográfico e económico, a população aumentou, surgindo novos conflitos relativos às dízimas, tornando-se necessária uma nova divisão das freguesias. Esta foi efetuada pelo bispo D. Frei Estêvão, a partir da Inquirição de 1309, mandada fazer pelo seu antecessor. Em diplomas datados de 1315 e 1317, Frei Estêvão atribuiu a cada uma das quatro igrejas da vila um território paroquial cujos limites rurais foram perfeitamente definidos, mas de que se silenciou a componente urbana. No caso concreto de Santa Maria do Castelo, a 25 de Julho de 1315, e de São Miguel a 19 de Agosto de 1317.

Outro edifício marcou, certamente, a urbe medieval torriense, na segunda metade do século XIV. Em 1366, os frades eremitas de Santo Agostinho obtiveram licença régia, para a fundação de um mosteiro graciano em Torres Vedras, depois de uma tentativa falhada, cem anos antes. Nesta sequência, embora desconheçamos a data, iniciar-se-ia a construção do edifício no sítio da Várzea Grande, defronte da igreja de São Tiago. Certo é que, em 1383, decorriam as obras e, em 1405, ainda a sacristia não tinha sido edificada. Foi seu prior Gonçalo, oriundo de Lagos, cuja inventio de santidade muito contribuiu para a edificação de um culto em torno das relíquias do 'padroeiro de Torres Vedras', desde o século XV, sobretudo como afirmação da canónica face ao novel convento de São Francisco inaugurado no Varatojo em 1474, que disputava com aquele a captação de vocações e influência. A Nossa Senhora da Graça dirigiam-se peregrinos chamados pela fé e pela presença das relíquias como uma expressão de culto. Os eremitas de Santo Agostinho ali permaneceriam até 1544 , momento em que se mudaram para o hospital de Santo André [igreja de Santo André da Gafaria], no exterior da porta de Sant'Ana, onde se encontra atualmente instalado o Museu Municipal Leonel Trindade.

Para além dos edifícios e das ruas referidos, a exemplo de outras vilas e cidades do reino, Torres Vedras ergueria as suas muralhas na centúria de quatrocentos. A primeira descrição que conhecemos da vila data de então, cabendo a Fernão Lopes, quando narra o cerco posto por D. João, Mestre de Avis, à alcáçova e ao castelo, entre o final de 1384 e o início de 1385, do seguinte modo:

«Este logar de Torres Vedras he dhũa fremosa mota, a quall natureza criou em tam ordenada igualldade, como se a maão fosse feita arteficialmente; teem boom e gracioso termo junto comssigo e arredor, de paães e vinhas e outros mantiimentos, que naquell tempo per aazo da guerra de todo pomto eram gastados. A villa tem sua cerca arredor do monte, e na mayor alteza delle esta o castello; e amtre a villa e o castello moravom tam poucos, de que nom he fazer comta; e toda sua poboraçom era em hũu gramde arravalde de muitas e boas casas, em bem hordenadas ruas ao pee do monte».

Em 1383, a vila não se encontrava amuralhada, encontrando-se a alcáçova e o castelo pouco povoados, uma vez que o espaço urbano se encontrava fora de muros (do castelo e alcáçova), num extenso arrabalde, na encosta virada a sul da mota do castelo, na sequência, aliás, do que acontecera desde, pelo menos, o período romano.

Para além da igreja de Santa Maria do Castelo e do paço dos Alcaides, poucas mais seriam as casas no recinto do castelo, como parece atestar a informação arqueológica (Luna \& Cardoso, 2013, p. 459).

Na urbe, sucessora do vicus romano, mas sem uma cerca, encontravam-se o açougue dos clérigos, a rua dos mercadores, a Judiaria, o Relego, a rua das olarias e a praça dos víveres. Por isso 
mesmo, pouco tempo depois do regresso do castelo à posse do monarca português, numa altura em que a ameaça de uma nova invasão castelhana continuava a pairar (pelo menos até ao Tratado de Paz com Castela, de 1411), decidiu-se cercar a vila. A decisão não deveria estar tomada ainda em 1393, momento em que a Colegiada de São Pedro emprazou uns pardieiros, lembrando ao foreiro a necessidade de os transformar em casa, ao mesmo tempo que estipulava o pagamento do foro de seis libras anuais, acrescentando, porém, se per ventura em algũu tenpo se cercar a villa e a dictas casas forem derrubadas per razom de cerca que se asy fezer, que vos nom seyades thudo a fazer as dictas casas nem outrosy a pagar a dicta pensom a nos como dicto he. Todavia, deveria estar presente a ideia da construção da muralha, cujo projeto seria conhecido publicamente, uma vez que se sabia, ainda que aproximadamente, o percurso por onde deveria passar a muralha.

Não conhecemos a data de início da sua construção, assim como da sua conclusão, nem tampouco se se teria concluído. Sabemos, porém, que as obras estavam em curso em 1411, data em que o vedor das obras do muro aparece como testemunha de uma escritura pública, e permaneciam em 1434. Ainda que um século depois, os argumentos da resposta dos Vereadores, procurador e homens-bons de Torres Vedras a D. João III acerca da intenção do monarca transferir a Universidade de Lisboa para a vila, em 1531, reforçam a nossa desconfiança acerca da sua não conclusão, uma vez que se aduzia que a vila não era cercada.

Também um inventário das propriedades da Colegiada de São Pedro, de 1488, refere a existência de um pardieiro que confrontava com o muro da vila junto ao Chafariz dos Canos, confrontando a Poente com o muro. Na verdade, as referências ao muro, sendo escassas, surgem, sobretudo, junto das portas, acrescendo a dificuldade, quando sabemos que existiam portas na urbe medieval que não atravessavam muralhas, tão simplesmente porque estas não existiam.

Quanto às portas, apenas a toponímia e as descobertas feitas por ocasião de algumas obras de construção civil têm permitido localizá-las, assim como determinar a direção das muralhas. A documentação medieval não faz referência a qualquer porta, referindo António Carvalho da Costa, na sua Corografia Portugueza, publicada em 1712, que no seu tempo ainda existiam três a da Várzea, a de Sant'Ana (junto à ermida de Santa Ana) e a da Corredoura - as mesmas três portas que a urbe medieval conhecera. A de Sant'Ana foi demolida em 1641, para permitir a ampliação e embelezamento do Largo da Graça. A da Várzea foi demolida em 1734, por ordem de D. Afonso V, servindo as suas pedras para a construção da calçada que dela partia para Mafra e Lisboa. Quanto à da Corredoura não se conhece a sua demolição, mas ainda hoje é visível uma parte de um pequeno torreão e muralha, junto ao Chafariz dos Canos, postas a descoberto por ocasião das obras num edifício defronte daquele.

A somar às três portas referidas alguns autores apontam a existência de uma quarta porta, baseando-se na referência de um documento de 1341 redigido ante a porta dos moynhos da Ponte Pedrinha. Mas parece-nos que tal referência aponta não para uma porta na muralha, mas para a porta dos próprios moinhos, o que não impede, porém, a existência de uma hipotética passagem, um postigo, que daria acesso a norte, provavelmente através da Ponte Pedrinha. A ocidente do castelo, deveria existir também outro postigo, que permitisse o acesso à igreja de $\mathrm{S}$. Miguel, talvez permitindo a passagem na Rua de Carcavelos, largamente citada na documentação medieval.

Junto à Porta da Corredoura, encontrava-se, desde a segunda década do século XIII um chafariz - o Chafariz dos Canos. A sua primeira referência data de 1322, quando o mosteiro de Santa Maria de Alcobaça doou uma soma de dinheiro a um homem para a construção dos 'canos da agoa que vem pera a villa' de Torres Vedras. A sua construção teve o patrocínio de D. Dinis (1279-1325), como atestam os representantes da vila e termo de Torres Vedras, Fernam d'Alvarez e João Gil, no pedido que dirigem, anos mais tarde, a D. Afonso V, nas Cortes de Lisboa de 1459, registados nos capítulos especiais:

"[...] Senhor, em esta vila há edificios de canos por que vem água a um chafariz que está na dita vila, que os reis que Deus tem, com ajuda dos moradores dela fizeram». 
O castelo, as igrejas matrizes, os paços - do concelho e régio, bem como o mosteiro de Nossa Senhora da Graça, e o chafariz dos Canos são bem o exemplo, desde a antiguidade até, pelo menos à Idade Média, de que os edifícios de poder marcavam simbolicamente o espaço urbano, pois, como refere Cristophe Picard, o edifício fazia a urbe (Picard, 2000, p.150).

A par dos edifícios do poder desenvolvia-se, nas ruas do casario, a atividade artesanal e comercial, com o açougue dos clérigos, o relego, as olarias, os pelames...

\section{Conclusão}

Assim, como bem notaram Isabel de Luna e Guilherme Cardoso, bem como André Duarte Baptista, com uma leitura inovadora do espaço, a matriz urbana fundacional de Torres Vedras é de origem romana (Luna e Cardoso, p.462), tendo os dois principais eixos viários - decumanus e cardo - marcado a estruturação da urbe medieval.

A exemplo de outras vilas e cidades do reino, a vila medieval torriense era polinucleada, organizando-se em torno de diversos centros, marcados por um edifício - sede de poder: os centros do poder político - paço do Concelho e paço régio, do poder militar - o castelo, e do poder religioso - as igrejas matrizes, o mosteiro de Nossa Senhora da Graça e a Judiaria.

Teriam as muralhas condicionado o crescimento da urbe e, sobretudo, o urbanismo pós medieval? Uma questão para a qual não temos resposta. Pois é necessário continuar a investigação para o século XVI de modo a melhor podermos responder a esta questão.

\section{Referências}

Baptista, A.J.D. (2013) O lugar como simbiose : centro histórico de Torres Vedras. (Dissertação de Mestrado) Universidade Lusófona de Humanidades e Tecnologias. Escola de Comunicação, Arquitectura, Artes e Tecnologias da Informação, Lisboa, Portugal.

Barbosa, P. G. (1992). Povoamento e Estrutura Agrícola na Estremadura Central: séc. XII a 1325. Lisboa: Instituto Nacional de Investigação Científica.

Figaniere, F. F. (1859). Memórias das Rainhas de Portugal. Lisboa: Typographia Universal, 252-255.

Lopes, F. (1973). Crónica del Rei Dom Joham I de Boa Memoria e dos Reis de Portugal o Decimo [reed. Facsimilada da ed. Anselmo Braamcamp Freire]. Lisboa: Parte Primeira.

Luna, I., \& Cardoso, G. (2013). «a urbe de Torres Vedras e a sua cerca medieval». In: I.C.F. Fernandes (coord.). Fortificações e território na Península Ibérica e no Magreb: séculos VI a XVI. Lisboa: Edições Colibri; Mértola: Campo Arqueológico, 457-471.

Mantas, V.G. (2001). “A População da região de Torres Vedras na época romana”. In: Turres Veteras IV: Actas de Pré-história e História Antiga. Torres Vedras: Câmara Municipal; Lisboa: Instituto Alexandre Herculano da Faculdade de Letras da Universidade de Lisboa, 129-141.

Picard, C. (2000). Le Portugal musulman : VIIIe - XIIIe : l'Occident d'al-Andalus sous domination islamique. Paris : Maisonneuve \& Larose.

Rodrigues, A. M. S. A. (1995). Torre Vedras: a vila e o termo nos finais da Idade Média. Lisboa: Fundação Calouste Gulbenkian.

Silva, C. G. da (2012). "Santa Maria e São Miguel ; São Pedro e São Tiago". In: J.M. Tavares, J.A. Madruga, \& C.G. da Silva. Medição do tempo em Torres Vedras. Torres Vedras : Câmara Municipal, 126 e 128-129.

Silva, C. G. da (2008). Torres Vedras antiga e medieval. Torres Vedras: Câmara Municipal; Lisboa: Colibri.

Sousa, J. M. C. (ed.) (1958). Fontes medievais de história Torreana. Torres Vedras: Câmara Municipal.

Tavares, J.M., Madruga, J.A., \& Silva, C.G. (2012). Medição do tempo em Torres Vedras. Torres Vedras: Câmara Municipal.

Vicente, A.B., et al. (2001). O foral medieval da vila de Torres Vedras: 15 de agosto de 1250. Torres Vedras: Câmara Municipal. 